\title{
LEI E ADIVINHAÇÃO NA REPÚBLICA ROMANA TARDIA*
}

FEDERICO SANTANGELO ${ }^{1}$

Tradução: Cláudia Beltrão
Resumo: Este artigo lida com as interseções entre lei e adivinhação na República romana tardia, enfocando principalmente a evidência de Cícero e alguns termos recorrentes em suas obras, notadamente divinatio e prudentia. Outros materiais comparativos farão parte da discussão, bem como a evidência de outros autores romanos, especialmente Plauto. É enfatizado um importante grau de afinidade entre lei e adivinhação e sua forte ligação com o conhecimento especializado e as respostas autorizadas. Palavras-chave: Adivinhação, predição, lei, previsão, jurisprudência, conhecimento, República romana, Cícero.

\section{INTRODUÇÃO}

Se alguém digitar "lei de adivinhação" em um site de busca, uma série de referências a dois interessantes eventos recentes surgirá. Em 1951, um

${ }^{1}$ Senior Lecturer in Ancient History. School of History, Classics and Archaeology, Newcastle University. estatuto foi aprovado pela Assembleia Geral da Carolina do Norte pelo qual era "ilegal para qualquer pessoa praticar as artes da frenologia, quiromancia, clarividência, adivinhação e outras técnicas de tipo similar nas regiões acima mencionadas". Em fins dos anos 90, uma coalizão de neopagãos, médiuns e autoproclamadas bruxas iniciaram uma campanha para a abolição da lei, que foi finalmente aprovada pela Assembleia Geral da Carolina do Norte em 2003, e endossada pelo Governador do Estado em 2004. Em dezembro de 2007, a Câmara do Tajiquistão aprovou uma lei punindo aqueles que se dedicassem à feitiçaria e à cartomancia com uma multa equivalente a aproximadamente 100 euros (entre trinta e quarenta vezes o valor do salário

2 Ver: http://www.oldenwilde.org/oldenwilde/gen info/ blk rib/nclaw info.html. Último acesso em 18/07/2016. A lei inclui uma importante exceção: ela não proíbe "a prática amadora da frenologia, quiromancia, cartomancia e clarividência em ambientes escolares ou religiosos, desde que realizados nos edifícios escolares ou religiosos." 
mínimo mensal do país). A lei teve um ativo apoio do Presidente Imomali Rakhmon, que ainda em 2007 aprovara novas leis introduzindo multas por casamentos e funerais extravagantes - uma revisitação das antigas leis suntuárias, suponho, apesar de o Presidente Rakhmon tê-las apresentado como parte de um programa de combate à pobreza. ${ }^{3} \mathrm{Em}$ 2015, "magia e bruxaria" foram criminalizadas e punidas com sentenças de até sete anos. ${ }^{4}$

Como se sabe, há evidencias de tentativas de limitar a adivinhação com medidas legais sob a República romana também. Pensemos nos eventos de $213 \mathrm{AEC}$, quando o Senado instruiu o pretor urbano para controlar os "sacrificadores e profetas" ( $s a$ crificuli ac uates) ativos em Roma e uma série de textos relativos a rituais divinatórios e sacrificiais foi confiscada; ou na expulsão dos astrólogos "caldeus" em 139 AEC. A famosa passagem de Catão de que o uilicus sob nenhuma circunstância deveria procurar o conselho do haruspex, do áugure ou do vidente caldeu, não pertence a um contexto legal, certamente, mas fala muito sobre as armadilhas

3 Ver: http://uk.reuters.com/article/oddlyEnoughNews/ idUKL1256765520071212, último acesso em 18/07/2016. Cf. também a recente decisão do Supremo Tribunal Mexicano em 2 de junho de 2010, na qual "a descrição de fraude tipificada contida no Código Penal do Estado de San Luis Potosí, que pude aquele que tirar proveito inadequado de preocupações, superstições ou da ignorância do povo, por meio de alegadas invocações espirituais, adivinhações ou curas ou outros procedimentos falhos em validade técnica ou científica" é declarada constitucional (texto completo disponível em http://sjf.scjn. gob.mx/sjfsist/Documentos/Tesis/164/164052.pdf, último acesso em 03/09/16).

4 Ver: http://en.news-4-u.ru/the-president-of-tajikistan-has-criminalized-witchcraft.html, último acesso em 03.09.16. Cf. também a recente decisão do Supremo Tribunal Mexicano em 2 de junho de 2010, na qual "a descrição de fraude tipificada contida no Código Penal do Estado de San Luis Potosí, que pude aquele que tirar proveito inadequado de preocupações, superstições ou da ignorância do povo, por meio de alegadas invocações espirituais, adivinhações ou curas ou outros procedimentos falhos em validade técnica ou científica" é declarada constitucional (texto completo disponível em http://sjf.scjn. gob.mx/sjfsist/Documentos/Tesis/164/164052.pdf, último acesso em 03/09/16). que a adivinhação descontrolada representava para alguém na posição de Catão. ${ }^{5}$

Neste artigo, contudo, não tenho a intenção de desenvolver a relação entre adivinhação e lei sob o ângulo da repressão e do controle. Eu gostaria de explorar as ligações e a interação entre a adivinhação e a lei em um sentido positivo, por assim dizer, discutindo as linhas de contato entre essas duas áreas cruciais da vida intelectual romana. As afinidades entre a adivinhação e a lei têm sido amplamente exploradas pela literatura especializada em uma série de diferentes culturas, especialmente do ponto de vista antropológico. O mais conhecido exemplo é, provavelmente, o dos Azande, a população centro-africana estudada pelo antropólogo inglês Edward Evans-Pritchard nos anos 1930, que usavam métodos divinatórios na solução de disputas judiciais: acreditava-se que uma galinha podia ser o agente que transmitiria a voz dos ancestrais. Levava-se ao animal uma questão sobre um crime que supostamente ocorrera: ele era, então, alimentado com veneno; se morresse, considerava-se uma resposta afirmativa; se sobrevivesse, o contrário era verdadeiro. A performance deste ritual assegurava uma decisão legítima; como tem sido observado, as galinhas têm uma função que não é conceitualmente distinta à da lei, conferindo legitimidade a um processo decisório. (EVANS-PRITCHARD, 1937; MANSELL, THOMSON, METEYARD, 2004, p. 31-35.)

O papel de práticas divinatórias similares em decisões legais tem sido observado em outros contextos culturais. O ritual conhecido como ordálio, no qual o acusado enfrenta injúrias potencialmente

\footnotetext{
${ }^{5}$ Confiscos em 213 AEC: Lívio, Ab urbe condita 25.1.6-12; 25.12. Expulsão dos astrólogos caldeus em 186 AEC: Valério Máximo, Facta et dicta memorabilia 1.3.3.; Catão, De agricultura 5.4: [vilicus] haruspicem, augurem, hariolum, Chaldaeum nequem consuluisse uelit. Cf. também, para o período imperial, as diversas tentativas para proibir a consulta a astrólogos e adivinhos de salute principis: ver, e.g., Ulpiano, Collatio 15.2.3; Paulo, Sententiae 5.21.3; Codex Theodosianus 16.10.12. Para uma recente reconsideração do lugar da astrologia na sociedade romana, ver RIPAT, 2011 e SANTANGELO, 2013, p. 246-258.
} 
fatais a fim de provar sua inocência, tem sido estudado entre os Efik, povo localizado na província da Calaba, na Nigéria, e também no Caribe (SIMMON, 1956, esp. p. 224. VAN DER VELDEN, 2008, p. 310329). ${ }^{6}$ É equivocado rejeitar o ordálio como uma prática pagã, ou uma prática confinada a cenários exóticos. Ela foi amplamente atestada em toda a Europa Alto-Medieval, em que "julgamentos pelo fogo e pela água" foram um importante fator do sistema jurídico criminal (BARTLETT, 1986). Na Inglaterra, esses julgamentos foram abolidos somente em 1215 , quando foram substituídos pelo advento do sistema dos júris, mas o uso de práticas divinatórias e mágicas para a detecção de criminosos continuou em contextos privados por muitos séculos. ${ }^{7}$

Voltando a contextos anteriores e completamente diferentes, na China do século III AEC, a interação entre lei e adivinhação surge em situações muito interessantes. Os túmulos de oficiais escavados em Yunmeng e Baoshan mostraram que textos legais desempenharam um papel no ritual funerário, e que, de fato, esses textos eram parte do material que supostamente acompanhava o morto à sua nova vida. Eles podiam incluir um grupo de regras sobre a conduta oficial ou sobre temas como a manutenção do registro público. O material descoberto no túmulo de Baoshan inclui alguns textos divinatórios, que têm a ver com procedimentos de exorcismos e purificação: o adivinho age como um médico, ou, de fato, como um juiz, identificando o espírito que estava causando uma doença e estabelecendo sua relação com o paciente. Um texto do túmulo Yunmeng lida com técnicas divinatórias que capacitam a apanhar um ladrão; aparentemente, o momento em que um crime ocorreu podia revelar algo sobre a identidade do agressor (LEWIS, 2007, p. 227-230). Uma recente obra sobre o Tibete do século VIII EC mostra que as decisões legais frequentemente envolviam o uso de cleromancia. O uso de dados ou dos manuais de adivinhação em contextos legais é bem atestado neste período e era um ele-

\footnotetext{
${ }^{6}$ Agradeço ao Dr. Van der Velden pelas discussões e apoio prático.

${ }^{7}$ Ver BAKER, 1990, p.5-6, 578-579. Sobre o fim das ordálias na Europa em geral, ver BARTLETT, 1986, p. 34-102; sobre desenvolvimentos posteriores, o ponto de partida é THOMAS, 1971, esp. p. 252-264.
}

mento essencial do complexo sistema legal e burocrático. $\mathrm{O}$ uso dos dados podia ter um papel central nos processos de decisão: magistrados os utilizavam como um instrumento para legitimar suas decisões ao atribui-las a poderes superiores (DOTSON, 2007, esp. p. 29-32). Contudo, é interessante que regras claras estabeleciam quando os dados podiam ser usados ou não: uma vez que um contrato entre duas partes fora concluído, a cleromancia não podia ser usada em uma disputa legal (DOTSON, 2007, p. 40). Como no caso de várias sociedades, a adivinhação só faz sentido no interior de um quadro específico de regras e restrições. As premissas conceituais dessas práticas são claras: ao delegar a solução de uma controvérsia legal a um procedimento divinatório o apoio divino é solicitado e o resultado do processo é integralmente legitimado (ROSENSTEIN, 1995; STEWART, 1998).

Outro aspecto da relação entre adivinhação e lei vem à tona em um ritual divinatório conhecido como namburbi, bem atestado no antigo Oriente Próximo; grande parte das evidências deste ritual vem da biblioteca do rei Assurbanipal (685 - c. 627 AEC), em Nínive. Namburbis eram baseados na premissa de que presságios são sinais da ira dos deuses, que eram enviados aos homens, exigindo uma resposta ritual apropriada. Os deuses então julgavam a adequação dessa resposta, como um tribunal o faria. A pessoa que recebera o sinal hostil se apresentava diante do tribunal dos deuses, pedindo-lhes que evitassem o destino que lhe fora atribuído. Se o ritual fosse bem sucedido, os deuses evitariam a punição prevista no presságio. Os rituais de extispicina tem um perfil similar: a tarefa do adivinho é estabelecer um veredito, endereçando-se aos deuses e pedindo-Ihes para dar um veredito no caso em discussão. A terminologia usada em contextos divinatórios é a mesma utilizada em contextos judiciais seculares. Shamash, o Deus Sol, que tinha um papel central em uma série de consultas divinatórias, é chamado "o senhor do veredito" e "Juiz do Céu e da Terra" (MAUL, 1999). A adivinhação é um instrumento que permite a produção de julgamentos divinos e provê um quadro no qual a lei divina é estabelecida.

O desenvolvimento da jurisprudência romana e a complexidade do contexto social no qual ela se formou são, em muitos aspectos, não comparáveis 
aos exemplos que foram discutidos até aqui. Vale a pena mencionar brevemente um caso isolado: uma passagem de Ulpiano mostra que quando um astrólogo ou um adivinho ilegal (qui aliquem illicitam diuinationem pollicetur) alegava que alguém era culpado de roubo, era passível de ser punido no caso de a alegação ser incorreta (embora eles não pudessem ser processados por difamação sob o edito pretoriano). ${ }^{8}$ Contudo, a afinidade epistemológica entre a adivinhação e a lei merece ser explorada no contexto da Roma republicana também, por várias razões. Em primeiro lugar, tanto a adivinhação quando a lei foram constituintes importantes da vida intelectual romana, e ambas tiveram um desenvolvimento excepcional, especialmente entre os séculos II e I AEC. A contribuição que tiveram no desenvolvimento da cultura romana e, de fato, na coesão do império, foi verdadeiramente notável. Com efeito, pode ser dito que o lugar da adivinhação e da lei na sociedade e na cultura romanas não é comparável em outros contextos e foi o resultado de desenvolvimentos típicos de, e peculiares a, Roma. Elas não têm qualquer paralelo em qualquer outra sociedade antiga, e são um importante aspecto do legado romano. Em segundo lugar, a adivinhação e a lei merecem ser discutidas em associação porque ambas foram muito importantes para a prática e o exercício do poder na República: ambas lidaram com questões do poder, influenciaram e dirigiram as escolhas das elites, e estiveram profundamente engajadas com as mudanças que o próprio conceito de poder sofreu nos últimos dois séculos da República. Em terceiro lugar, a adivinhação e a lei eram ambas profundamente afetadas pelas alterações na cultura romana neste mesmo período. Foram ambas afetadas pela emergência de discursos profissionais competidores entre os séculos II e I AEC. Desenvolvimentos tão diversos quando a emergência da

\footnotetext{
${ }^{8}$ Digesta 47.10.15.13 (Ulpiano 77 ad ed.): si quis astrologus vel qui aliquem illicitam divinationem pollicetur consultus aliquem furem dixisset, qui non erat, iniuriarum cum eo agi non potest, sed constitutions eos tenent (Se algum astrólogo ou alguém oferecendo outra forma de clarividência ilícita, ao ser consultado, disser que outro alguém é um ladrão quando não o é, não haverá ação on injúria contra ele, mas ele é responsabilizado segundo os termos dos decretos imperiais, trad. baseada em Joseph A. C. Thomas). Sobre esta passagem, ver FÖGEN, 1993, p. 57-58.
}

jurisprudência romana, a crescente influência dos harúspices nos negócios políticos romanos, a chegada das teorias gramaticais helenísticas a Roma, a ascensão da literatura antiquária e geográfica, e mesmo a iniciativa estatal que levou à elaboração do novo corpus dos Livros Sibilinos após o incêndio de 83 AEC são, todos, aspectos das mudanças culturais complexas que ocorreram nas últimas décadas da República. Esses processos levaram a uma considerável extensão do escopo do debate intelectual romano e, por outro lado, à emergência de novos ramos do conhecimento especializado. Em quarto lugar, tanto adivinhos quanto advogados, em Roma e alhures, expressavam usualmente seus conhecimentos através de sentenças de experts e respostas - em latim, responsa. Essas eram uma forma especifica de aconselhamento especializado, o qual podia ser especifico e genérico, particular e universal, intrusivo e não vinculante, dependendo da ocasião, do clima e do contexto nos quais eram praticadas e produzidas. ${ }^{9}$ Finalmente, e talvez mais significativamente, a lei e a adivinhação eram, ambas, formas de controle do futuro ou, de fato, tentativas de assegurar tal controle. ${ }^{10}$ Eram, ambas, formas especificas e especializadas de predição.

\footnotetext{
${ }^{9}$ Sobre o lugar dos responsa na cultura tardo-republicana ver RAWSON, 1985, p. 201-206, e SCHIESARO, 2007, p. 62-90, 71-
} 73.

${ }^{10} \mathrm{Cf}$. Cicero, De legibus 1.19: itaque arbitrantur prudentiam esse legem, cuius ea vis sit, ut recte facere iubeat, vetet delinquere, eamque rem illi Graeco putant nomine nomon suum cuique tribuendo appellatam, ego nostro a legendo. nam ut illi aequitatis, sic nos delectus vim in lege ponimus, et proprium tamen utrumque legis est. quod si ita recte dicitur, ut mihi quidem plerumque videri solet, a lege ducendum est iuris exordium. ea est enim naturae uis, ea mens ratioque prudentis, ea iuris atque iniuriae regula (E então eles acreditam que a lei é a inteligência, cuja função natural é comandar a conduta correta e proibir os erros. Eles pensam que esta qualidade deriva seu nome em grego da ideia de garantir a cada um o que é seu, e na nossa linguagem isso foi nomeado a partir da ideia de escolha. Pois assim como eles atribuíram a ideia de equidade à palavra lei, nós lhes demos a de escolha, embora ambas as ideias se apliquem adequadamente à lei. Agora, se isso é correto, como penso que é em geral, então a origem da justiça deve ser encontrada na lei, pois a lei é uma força natural; ela é a mente e a razão do homem inteligente, o padrão pelo qual justiça e injustiça são medidas; trad. Clinton W. Keynes, modificada). Ver as valiosas observações sobre a analogia entre jurisprudência e ciência augural em HARRIES, 2006, p. 166-168. 
Com este pano de fundo, pretendo me concentrar em três problemas neste artigo. Primeiro, eu lidarei com o debate tardo-republicano sobre a relação entre augúrio e adivinhação, que pode ser entendido como parte de uma reflexão mais ampla sobre a lei augural. Em segundo lugar, discutirei alguns usos da palavra diuinatio em um contexto legal, tentando considerar como as fronteiras entre adivinhação e lei foram debatidas e definidas entre os séculos II e I AEC. Por fim, explorarei os conceitos de prudentia e prudens, cuja relação com as esferas divinatória e legal exige uma análise mais aprofundada.

\section{AUgÚRIO VS AdIVINHAÇÃo?}

\section{Comecemos pelo Livro 1 do De divinatione de} Cícero. Qualquer que seja o viés escolhido para a interpretação do diálogo (e devo confessar que sou parte de uma minoria que o vê como uma séria crítica da adivinhação e de sua função pervasiva na política e na sociedade romana), é incontroverso que a polemica entre Quinto e Marco se torna às vezes bastante agressiva. ${ }^{11} \mathrm{O}$ ponto mais forte de Quinto é que o próprio Marco é um áugure e não pode defender o caso contra a adivinhação com credibilidade (1.105). De fato, ele deveria fazer a "defesa" dos auspicia: auspiciorum patricinium. ${ }^{12} \mathrm{~A}$ resposta de Marco é extremamente interessante: o augúrio não deve ser visto como uma forma de adi-

\footnotetext{
${ }^{11}$ Estou, portanto, mais inclinado a seguir LINDERSKI, 1982, e TIMPANARO, 1994, que BEARD, 1986, e SCHOFIELD, 1986; ver SANTANGELO, 2013, p. 10-36. Quinto repetidamente acusa Marco de ser inconsistente em relação à adivinhação: De divinatione 1.12 .19 (prodígios anunciando a conspiração de Catilina) - resposta em 2.20.46; De divinatione 1.28.59 (um sonho com Mário) - resposta em 2.67.140; De divinatione 1.32.68 (sua reação ao presságio antes de Farsália) - resposta em 2.55.114. Para uma diferente interpretação da polêmica entre Quinto e Marco, ver SCHULTZ. 2009, p. 202-205.

${ }^{12}$ Cicero, De divinatione 1.47.105 [fala de Quinto]: quid de auguribus loquar? tuae partes sunt, tuum, inquam, auspiciorum patrocinium debet esse (Porque eu preciso falar dos áugures? Este é o teu círculo, digo, e a defesa dos auspícios tem de ser tua). Scheid (1987-1989, p. 127-128) destaca que algumas características do de divinatione remetem à oratória judicial: o uso do termo quaestio é significante neste ponto, e esta ocorrência de patrocinium também.
}

vinhação. Ele é um áugure romano, não um áugure marso, e a adivinhação não é parte de sua competência. Ele não é o tipo de áugure que prediz o futuro pela observação do voo dos pássaros, ou "pela observação de outros signos" (2.70); mais tarde, ele diz que as antigas ciências augurais eram apenas superstição. ${ }^{13} \mathrm{~A}$ tarefa do áugure é realizar um ritual e interpretar os signos de não hostilidade dos deuses. Marco admite que originalmente o augúrio fosse visto como tendo uma dimensão divinatória, e que a ciência augural era capaz de predizer o futuro, mas esta interpretação fora então superada - a antiguidade estava errada em muitos aspectos, diz Marco.

O conhecimento augural tinha como objeto o ritual, não a predição: este é um fator crucial de diferenciação deste conhecimento da disciplina etrusca. Nós precisamos observar o desenvolvimento da adivinhação pública em Roma, incluindo a ascensão dos harúspices ao centro da arena política romana e seu crescente sucesso no século II AEC: foi a partir da sua ascensão que encontramos profecias explicitas e detalhadas se tornando parte do discurso público. ${ }^{14}$ Marco advoga que o augúrio é baseado

${ }^{13}$ Cícero, De divinatione 2.70 [fala de Marco]: 'difficilis auguri locus ad contra dicendum.' Marso fortasse, sed Romano facillumus. non enim sumus ii nos augures, qui avium reliquorumue signorum observatione futura dicamus. et tamen credo Romulum, qui urbem auspicato condidit, habuisse opinionem esse in providendis rebus augurando scientiam (errabat enimmultis in rebus antiquitas), quam vel usu iam vel doctrina vel vetustate immutatam uidemus; retinetur autem et ad opinionem vulgi et ad magnas utilitates rei publicae mos, religio, disciplina, ius augurium, collegio auctoritas. ("Argumentar contra os auspícios é uma tarefa difícil, você diz, para um áugure fazer". Sim, para um marso, talvez; mas muito fácil para um romano. Pois nós, áugures romanos, não somos o mesmo tipo de áugures que preveem o futuro pela observação do voo dos pássaros e outros signos. E, também, acredito que Rômulo, que fundou a cidade pelos auspícios, acreditava que o augúrio era uma arte útil para prever as coisas que virão, pois os antigos tinham visões equivocadas em muitos assuntos; mas nós percebemos que a arte sofreu mudanças, devido à experiência, educação, ou ao longo lapso de tempo. Contudo, por respeito à opinião das massas e por causa do grande serviço ao Estado, as práticas augurais, a disciplina, os ritos religiosos, as leis e a autoridade do colégio augural foram mantidos).

${ }^{14}$ Os vates que atuavam na Roma republicana também produziam profecias, mas elas raramente eram reconhecidas ou incluídas no quadro institucional da adivinhação pública: cf. a notável exceção dos carmina Marciana, em Lívio, Ab urbe condita 25.12. Ver SANTANGELO, 2013, p. 149-173. 
em um grupo diferente de práticas. Os áugures interpretam signos augurais, que são avisos, ou signos de que uma ação é permitida pelos deuses. Eles não revelam o veredito do destino, nem antecipam o resultado de qualquer ação.

Esta passagem é apenas um momento em um debate técnico vívido e complexo. Cicero desenvolve o tópico de modo aprofundado em uma obra em que supostamente se dedicou ao problema, um tratado De auguriis. ${ }^{15}$ Cícero não se refere a ele em De divinatione, e a discussão sobre a ciência augural é encerrada por uma breve promessa de lidar com o problema de modo aprofundado em outra ocasião; isso provavelmente significa que o tratado ainda não tinha sido publicado em $44 \mathrm{AEC}$, ou mesmo que ainda não tinha sido escrito. De todo modo, é certo que Cicero estava reunindo informações detalhadas sobre o tópico ainda em 50 , durante seu governo na Cilicia, quando escreveu a seu companheiro áugure Ápio Claudio Pulcro solicitando que lhe enviasse uma cópia de sua obra sobre o augurato. ${ }^{16}$

O resultado desta pesquisa pode ser encontrado em uma importante passagem do De legibus (2.32-33), quando Ático diz explicitamente que alguns membros do colégio augural pensavam que os auspícios existiam somente para o bem da República, enquanto outros afirmavam que eles estavam em pé de igualdade com a adivinhação (disciplina vestra quase divinare videatur posse). ${ }^{17}$

15 Evidências para o De auguriis de Cícero: Cícero, De divinatione 2.76; Cicero, Ad familiares 3.9.3. no tocante à literatura tardo-republicana sobre os augúrios e os auspícios ver HARRIES, 2006, p. 164-166.

${ }^{16}$ Cicero, De divinatione 2.74-75; Ad familiares 3.9.3 (escrita em Laodiceia, em $50 \mathrm{AEC}$ ). Cicero já tinha recebido o que parece ser a primeira parte da obra em junho de 51 AEC (illo libro augurali), que the era dedicada: Ad familiares 3.4.1.

${ }^{17}$ Cícero, De legibus 2.32-33. Ático: sed est in conlegio vestro inter Marcellum et Appium optimos augures magna dissensio- nam eorum ego in libros incidi-, cum alteri placeat auspicia ista ad utilitatem esse rei publicae composita, alteri disciplina vestra quase divinari videatur posse. hac tu de re quaero quid sentias. Marcus: egone? divinationem, quam Graeci mantiken appellant, esse sentio, et huius hanc ipsam partem quae est in avibus ceterisque signis (quod) disciplinae nostrae. si enim deos esse concedimus, eorumque mente mundum regi, et eosdem hominum consulere generi, et posse nobis signa re-
A resposta de Cícero é complexa, e parece, à primeira vista, estar em desacordo com o ponto de vista expresso no De divinatione, 2: a adivinhação existe, e observar o voo dos pássaros é um de seus aspectos, e uma das prerrogativas do augúrio. Contudo, a ciência augural (disciplina et ars augurum) sofreu um claro declínio através dos séculos - et vetustate et neglegentia. No entanto, o augúrio já não tem uma função divinatória, a despeito do que seu companheiro áugure Ápio pensava, apesar de esta ainda ser usada, a despeito do que Marcelo,

rum futurarum ostendere, non video cur esse diuinationem negem. sunt autem ea quae posui, ex quibus id quod volumus efficitur et cogitur. lam vero permultorum exemplorum et nostra est plena res publica et omnia regna omnesque populi cunctaeque gentes, (ex) augurum praedictis multa incredibiliter vera cecidisse ... nec vero Romulus noster auspicato urbem condidisset, neque Atti Navi nomen memoria floreret tam diu, nisi omnes hi multa ad veritatem admirabilia dixissent. sed dubium non est quin haec disciplina et ars augurum evanuerit iam et vetustate et neglegentia. ita neque illi adsentior qui hanc scientiam negat umquam in nostro collegio fuisse, neque illi qui esse etiam nunc putat. quae mihi videtur apud maiores fuisse duplex, ut ad rei publicae tempus non numquam, ad agendi consilium saepissime pertineret (Ático: ...mas há um grande desacordo em nosso colégio entre Marcelo e Ápio, ambos excelentes áugures; pois eu consultei seus livros $e$ percebi que um pensa que os auspícios foram inventados para a utilidade do Estado, enquanto o outro pensa que sua arte é realmente capaz de adivinhação em algum grau. Eu gostaria de saber tua opinião sobre esta questão. Marco: Minha opinião? Parece-me que uma arte da adivinhação, chamada mantike pelos gregos, realmente existe, e que um ramo dela é esta arte particular que lida com a observação dos pássaros e outros signos - este ramo pertence à nossa romana ciência dos augúrios. Pois se admitimos que os deuses existam, e que o universo é regido por sua vontade, que eles estão atentos à raça humana, e que eles têm o poder de nos dar indicações sobre eventos futuros, então eu não vejo nenhuma razão para negar a existência da adivinhação... Além disso, os registros da nossa República, assim como os registros de todos os reinos, povos e raças, são plenos de múltiplas instâncias de maraviIhosa confirmação das predições dos áugures sobre eventos subsequentes... Nem teria sido o caso de nosso próprio Rômulo tomar os auspícios antes de fundar Roma, nem o nome de Atio Navio seria rememorado todos esses anos, nem todas essas pessoas teriam feito profecias de notável acordo com a verdade. Mas, não há dúvida de que esta arte e ciência dos áugures tenham agora deixado de existir por conta da passagem do tempo e da negligência dos homens. Assim, eu não posso concordar com Marcelo, que nega que esta arte nunca foi possuída por nosso colégio, nem eu subscrevo a opinião de Ápio de que nós ainda a possuímos. O que creio é que entre nossos ancestrais ela teve um duplo uso, sendo às vezes empregada em crises políticas, mas, com mais frequência na decisão do curso de uma ação. Trad. de Clinton W. Keyes, modificada). 
outro membro do colégio, acreditava. A contradição com o De divinatione não é muito profunda, afinal. Cícero claramente diz que não está envolvido em práticas divinatórias; a interpretação do augúrio no passado é apenas parcialmente significativa, e se ajusta bem com a celebração da Roma primitiva que é típica do De legibus. Em segundo lugar, o escopo geral e o propósito do De legibus deve ser considerado. Trata-se de uma obra que se propõe a estabelecer uma série de princípios, regras e instituições para uma comunidade ideal; Cícero pensa que o augurato é uma instituição valiosa, e precisa justificar sua existência usando argumentos mais positivos do que os que utiliza no de divinatione. A declaração em favor da existência da adivinhação não é, então, surpreendente. O De legibus é uma obra na qual o tema do consenso e da concórdia é forçosamente marcado, como é esperado no caso de uma obra que pretende estabelecer regras gerais; neste contexto não é surpreendente que Cícero escolhesse não criar uma questão discordante, provendo um elogio genérico à adivinhação. Além disso, não se deve esquecer que não há evidência de que o De legibus tenha sido publicado enquanto Cícero estava vivo, enquanto já evidencias de que o De divinatione o foi. O que é frequentemente interpretado como uma contradição na visão ciceroniana do augúrio não foi percebida como tal por seus contemporâneos, e isso deve ser visto, afinal, como um desenvolvimento tardio da abordagem de Cícero ao problema. Os anos que separam o início da composição do De legibus da composição do De divinatione foram extremamente intensos para Cícero, e tiveram um grande impacto sobre ele. Daí a diferença de abordagem.

\section{Divinatio}

Não é surpreendente que Cícero faça amplo uso da palavra divinatio no de divinatione ${ }^{18}$. Mais importante ainda, ele fornece uma definição do que a palavra significa neste contexto no próprio inicio do livro 1: divinationem, quam Graeci

${ }^{18}$ Ver SANTANGELO, 2013, p. 47-56. mantiken appellant, id est praesensionem et scientiam rerum futurarum. ${ }^{19} \mathrm{Em}$ grande medida, o que nós entendemos por adivinhação romana ainda se baseia nesta definição, e este é um resultado da construção ciceroniana da divinatio. Muito da ambiguidade que encontramos nas ocorrências anteriores do termo divinatio na obra de Cícero é reduzida, e mesmo neutralizada por esta definição. Antes de tudo, um paralelo grego é claramente produzido: mantike, a arte dos adivinhos e videntes gregos. A relação etimológica e conceitual entre adivinhação e os deuses não é atendida pelo paralelo e não está em pauta. A adivinhação é um método que permite uma percepção antecipada do futuro: praesensio não implica o uso de categorias lógicas. Mas seria redutor confiná-la a esta esfera. A adivinhação é também uma forma totalmente legítima de conhecimento: ela é uma scientia.

A história do substantivo divinatio é instrutiva. Ele não é detectada antes de Cícero, e sua presença em autores pós-ciceronianos é um tanto esporádica, o que certamente não reflete o lugar que a adivinhação teve na cultura romana. $O$ verbo divinare parece já em Plauto, em um contexto realmente instrutivo. Pirgopolinices está escondido em um quarto e Acrotelêucio reconhece sua presença ao notar seu cheiro no quarto. O miles gloriosus diz para si mesmo (Mil, 1257): quia me amat, propterea Venus fecit eam ut divinaret. A habilidade de adivinhar deriva de uma forma de inspiração divina: mesmo em um contexto cômico, o conceito básico que sustenta o ato de adivinhar é enunciado com clareza. É visível,

\footnotetext{
${ }^{19}$ Cicero, De divinatione 1.1: vetus opinio est iam usque ab heroicis ducta temporibus, eaque et populi Romani et omnium gentium firmata consensu, versari quandam inter homines divinationem, quam Graeci mantiken appellant, id est praesensionem et scientiam rerum futurarum. magnifica quaedam res et salutaris, si modo est ulla, quaque proxime ad deorum vim natura mortalis possit accedere ("Há uma antiga crença, proveniente dos tempos míticos e firmemente estabelecida pelo acordo geral do povo romano e de todas as nações, que algum tipo de adivinhação existe entre os homens; isto é o que os gregos chamam mantike - isto é, a clarividência e o conhecimento dos eventos futuros. Ela é uma coisa realmente esplêndida e útil - se tal faculdade existe - desde que por ela os mortais podem se aproximar do poder dos deuses", trad. baseada em William A. Falconer).
} 
ao mesmo tempo, que o verbo divinare já tinha também dois sentidos: ele podia ser usado para se referir a uma adivinhação divinamente inspirada, que podia também ser profética, ou podia simplesmente se referir a uma suposição muito hábil. Não devemos nos restringir ao uso ocasional de divinare no contexto cômico; por outro lado, deve-se notar que o sentido complexo do verbo já era claro para Plauto, e seguramente para sua audiência. Não podemos dizer até que ponto essa percepção já levava a algum tipo de reflexão crítica sobre o escopo e os limites da adivinhação.

O sentido de divinare como "fazer uma previsão difícil" aparece em uma passagem da Hecyra de Terêncio: plane hic divinat (696: "é claro que ele prevê corretamente"). Ocorre também em uma passagem de Cícero no Pro Quinctio, seu primeiro discurso preservado, no qual ele ataca o modo pelo qual Névio prevê as intenções de Quinctio: “Em que momento, Névio, você pensa que Quinctio deveria ser defendido em sua ausência, ou como? Então, quando você pediu licença para tomar posse de seus bens? Ninguém estava presente, pois ninguém poderia imaginar (neque enim quisquam divinare poterat) que você iria fazer este pedido; nem diz respeito a ninguém objetar que o que o pretor decidiu não deve ser feito absolutamente, mas deve ser feito de acordo com seu edito". ${ }^{20}$ Neste caso, há uma ênfase diferente no uso do termo - quase um toque mordaz. Ninguém poderia razoavelmente adivinhar as intenções de Névio; somente um adivinho poderia tê-lo feito.

No contexto legal divinare podia ter uma clara conotação negativa. No Pro Plancio, Cícero acusa

\footnotetext{
${ }^{20}$ Cícero, Pro Quinctio 19.60-61: quo tempore existimas oportuisse, Naevi, absentem Quinctium defendi aut quo modo? tum cum postulabas ut bona possideres? nemo adfuit; neque enim quisquam divinare poterat te postulaturum, neque quemquam attinebat id recusare quod praetor non fieri, sed ex edicto suo fieri iubebat ('Em que momento, Névio, você acha que Quinctio deveria ter sido defendido em sua ausência, e como? Então, quando você estava pedindo licença para tomar posse dos bens dele? Ninguém estava presente, pois ninguém poderia imaginar (divinare) que você faria tal demanda; a ninguém tampouco cabe objetar que o que o pretor ordenou não seja absolutamente feito, mas sim fazer o que deve ser feito de acordo com seu edito. Trad. baseada em Charles D. Yonge).
}

seu adversário Laterensis por se recusar a ter um julgamento diante de um grupo de juízes que poderia expressar um parecer fundamentado sobre o caso. Os juízes que ouviram o caso eram homens de uma tribo diferente, e não podiam chegar a um julgamento plenamente fundamentado, porque eles não estavam a par de todas as circunstancias do caso: eles teriam de lançar mão de um método divinatório, em vez de usar as informações que homens em sua posição necessitavam para chegar a um parecer fundamentado. A frase é muito forte: cur denique se divinare malueris quam eos qui scirent iudicare ? ${ }^{21}$ Parece que em um contexto judicial a habilidade de "conjecturar" é considerada uma suposição irracional. Há outras passagens nas quais Cícero explora a fronteira fluida entre conjectura e adivinhação: ele o faz no Pro Cluentio e, mais claramente, no De inventione, em uma passagem na qual discute os limites da ratiocinatio ('raciocínio', 'inferência lógica') e a interpretação de textos legais mal redigidos. ${ }^{22}$

A palavra divinatio era também um termo legal específico: ela era usada para definir um tipo particular de discurso judiciário, que era pronunciado por um potencial acusador diante do júri, a fim de provar suas credenciais e ser designado como acusador em um caso. Somente uma divinatio sobreviveu, a Divinatio in Q. Caecilium, um discurso que Cícero pronunciou antes do julgamento de Verres, no qual ele atacou o questor de Verres, Q. Cecílio, e apresentou um sumário dos crimes de Cecílio e de Verres, além de uma descrição de suas próprias credenciais. Suetônio ainda teve acesso à divinatio que César pronunciou em 77 AEC a fim de conseguir ser o acusador de Cn. Cornélio Dolabella (cos. 81 $A E C)$, um antigo governador da Macedônia que foi acusado de uma série de ofensas contra os provinciais; de acordo com o biógrafo, uma parte significativa do discurso era derivada do famoso discurso de

${ }^{21}$ Cícero, Pro Plancio 28.46: “por que você prefere aqueles que procedem com base em conjecturas (divinare), em vez daqueles homens que podem decidir com base no conhecimento da verdade?" (Trad. baseada em Charles D. Yonge).

${ }^{22}$ Cícero, Pro Cluentio 97 e 131. Cícero, De inventione 2.50. Ver também Cícero, Pro Roscio Amerino 96; Pro Tullio 50; Pro Rabirio 1.2. 
César Estrabão para o povo de Sardes. ${ }^{23}$ Não é surpreendente que a divinatio fosse fortemente calcada em discursos anteriores: não eram provas materiais que estavam sendo discutidas no caso, mas a habilidade retórica do candidato a acusador.

Apesar de não termos muitas evidencias deste tipo de discurso, temos um bom número de tentativas de se definir o que era a divinatio, e de explicar a etimologia da palavra. O ponto de partida é a breve referência de Quintiliano às divinatione, na qual ele menciona a cause célèbre de Cícero e sua abordagem direta do discurso. Na visão de Cicero, o principal objetivo de um discurso de accusatore constituendo (sobre a designação do acusador) deve ser provar que um dado acusador é a escolha mais adequada para o grupo que está movendo a acusação, e o menos desejável para o acusado. ${ }^{24}$ Quintiliano segue uma linha diferente, e argumenta que os objetivos principais devem ser distintos: por que alguém está apto para agir como acusador em um caso determinado; se ele pode ser o mais forte patrono de um caso específico; se ele agiria como um acusador honesto. Neste caso, a discussão da divinatio é integralmente desenvolvida do ponto de vista do júri que deve escolher o acusador; os aspectos incertos desta decisão são enfatizados.

Mais significativo para nossos propósitos, Aulo Gélio traz algumas especulações documentadas sobre a etimologia da palavra. ${ }^{25}$ De acordo com a

${ }^{23}$ Suetônio, Divus Julius 55. 2. Sobre o julgamento de DolabeIla, ver GRUEN. (1966), p. 387-389.

${ }^{24}$ Quintiliano, De institutione oratoria 7.4.33: de accusatore constituendo, quae iudicia divinationes uocantur: in quo genere Cicero quidem, qui mandantibus sociis Verrem deferebat, hac usus est divisione: spectandum a quo maxime agi velint ii quórum de ultione quaeritur, a quo minime velit is qui accusatur (Há casos que concernem à indicação de um acusador, que são conhecidos como divinatione. Neste sentido, Cícero, que estava processando Verres no interesse de nossos aliados sicilianos, adota a seguinte divisão - em termos que o principal ponto a considerar é por quem aqueles que buscam a reparação dos erros que constituem o objeto em julgamento preferem ser representados, e por quem o acusado menos desejaria ser representado (trad. baseada em Harold E. Butler).

${ }^{25}$ Gélio, Noctes Atticae 2.4.1: quam ob causam Gavius Bassus genus quodam iudicii 'divinationem' appellari scripserit; et quam alii causam eiusdem vocabuli dixerint. cum de obra De origine vocabulorum de Gávio Basso, o termo deriva da natureza do julgamento que era esperado dos jurados: eles tinham que adivinhar qual a melhor escolha a fazer. Gélio observa que esta definição é parcialmente correta, pois a evidência na qual os jurados podiam apoiar sua decisão era tão escassa que sua decisão podia ser comparada a

constituendo accusatore quaeritur iudiciumque super ea re redditur, cuinam potissimum ex duobus pluribusve accusatio subscriptiove in reum permittatur, ea res atque iudicum cognitio 'divinatio' appellatur. id vocabulum quam ob causam ita factum sit, quaeri solet. Gavius Bassus in tertio librorum, quos de origine vocabulorum composuit: 'divinatio' inquit'iudicium appellatur, quoniam divinet quodammodo iudex oportet, quam sententiam sese ferre par sit.' nimis quidem est in uerbis Gaui Bassi ratio inperfecta uel magis inops et ieiuna. sed videtur tamen significare velle idcirco dici 'divinationem', quod in aliis quidem causis iudex ea, quae didicit quaeque argumentis vel testibus demonstrata sunt, sequi solet, in hac autem re, cum eligendus accusator est, parva admodum et exilia sunt, quibus moveri iudex possit, et propterea, quinam magis ad accusandum idoneus sit, quasi divinandum est. hoc Bassus. sed alii quidam divinationem' esse appellatam putant, quoniam, cum accusator et reus duae res quasi cognatae coniunctaeque sint neque utra sine altera constare possit, in hoc tamen genere causae reus quidem iam est, sed accusator nondum est, et idcirco, quod adhuc usque deest et latet, divinatione supplendum est, quisnam sit accusator futurus (A razão apontada por Gávio Basso para chamar divinario a certo tipo de inquérito judicial, e as explicações que outros deram sobre o mesmo termo. Quando o inquérito visa à escolha do acusador, e o julgamento se desenrola sobre a questão de a qual das duas ou mais pessoas a acusação de um réu, ou uma parte da acusação, deve ser confiada, este processo e exame pelos jurados é chamado divinatio. O motivo para o uso deste termo é tema de discussões frequentes. Gávio Basso, no terceiro livro de sua obra Sobre a origem das palavras, diz: "Este tipo de julgamento é chamado divinatio porque o jurado deve, de certo modo, adivinhar que veredito é o melhor a dar". A explicação dada nessas frases de Gávio Basso está longe de ser completa, ou melhor, é inadequada e frágil. Mas, ao menos ele parece ter tentado mostrar que divinatio é usada porque em outros julgamentos costuma ocorrer que o jurado seja influenciado pelo que ele ouve e pelo que é demonstrado por provas ou por testemunhas; mas, neste caso, quando um acusador precisa ser designado, as considerações que podem influenciar um jurado são muito frágeis e escassas, e por isso ele deve, por assim dizer, 'adivinhar" que homem é o mais apto a fazer a acusação. Assim pensa Basso. Mas alguns outros pensam que a divinatio é assim chamada porque, como acusador e acusado são dois elementos que são, como o são, relacionados e conectados, então nenhum pode existir sem o outro, nesta forma de julgamento, enquanto já há um acusado, não há ainda um acusador - e assim o fator que está faltando e é desconhecido - designadamente que homem será o acusador - pode ser fornecido pela adivinhação. Trad. baseada em John C. Rolfe). Cf. o verbete divinatio em MALTBY, 1991, p. 192-193. 
um ato divinatório. Ele acrescenta, contudo, que a palavra divinatio poderia ter uma origem diferente: desde que o acusador e o acusado são, ambos, partes integrantes do julgamento, e um não pode existir sem o outro, na fase que precede o julgamento a figura do acusador, que ainda não fora designada, tem de ser estabelecida pela adivinhação - imaginando-se que o acusador esteja realmente no local.

O Pseudo-Ascônio apresenta uma definição muito mais direta, e seguramente mais interessante. ${ }^{26}$ De acordo com o comentador anônimo, que fornece algumas observações introdutórias sobre a Divinatio in $Q$. Caecilium que abre o corpus das Verrinas, a divinatio é um subgênero particular da oratória. Ele então lista algumas teorias sobre a etimologia da palavra, que são, de fato, relevantes para a interpretação do próprio exercício. Stangl pode estar certo ao notar que a natureza da obra do Pseudo-Ascônio é compilatória, mas é precisamente a esta disposição de registrar definições diferentes que devemos a menção dessas teorias (STANGL, 1909, p. 12). Segundo algumas, que seguem uma linha muito próxima à de Gávio Basso e de Gélio, o discurso era um exercício de adivinhação, porque ele tinha de ser uma especulação fundamentada sobre o futuro desenvolvimento do julgamento, e sobre a pessoa a quem deveria ser confiada a acusação. Segundo outros, a ênfase estava nos juízes. A palavra supostamente derivava do fato de que os juízes deveriam ouvir os pleiteantes a acusador do caso sem que tivessem proferido o juramento, de

\footnotetext{
${ }^{26}$ Pseudo-Ascônio, 186 Stangl: divinatio dicitur haec oratio, quia non de facto quaeritur et coniectura, sed de futuro, quae est divinatio, uter debeat accusare. alii ideo putant divinationem dici, quod iniurati iudices in hac causa sedeant, ut, quod velint, praesentire de utroque possint; alii, quod res agatur sine testibus, et sine tabulis, et his remotis, argumenta sola sequantur iudices, et quasi divinent (Este discurso é chamado divinatio porque ele procede por conjecturas e não lida com fatos, mas ele lida com o futuro, pois decide quem deve liderar o processo. Outros pensam que ele é chamado divinatio porque os juízes lidam com o caso sem ter feito um juramento, e isso para que sejam capazes de formar uma impressão sobre ambos os acusadores. Outros argumentam que, uma vez que a questão é discutida sem testemunhas e sem provas escritas, e na verdade de modo apartado deste tipo de material, os juízes se apoiam somente nos argumentos, e quase adivinham).
}

modo a estarem aptos a tomar uma decisão livre sobre eles. A natureza divinatória deste exercício é confirmada pelo uso do verbo prasentire: de acordo com a definição operação de Cícero no início do De divinatione, a divinatio é uma praedictio (predição) e uma praesensio (pressentimento) das coisas que geralmente consideradas fortuitas. Um terceiro grupo de intérpretes concorda em um aspecto importante, segundo o qual a etimologia da palavra deriva da natureza da tarefa dos juízes: eles tinham a difícil tarefa de decidir quem seria o melhor acusador, apesar de não terem qualquer evidência prévia sobre o caso. Eles eram obrigados a se basearem nos argumentos dos oradores, e não podiam basear seu julgamento em qualquer outra coisa senão nisso. Nesse sentido seu exercício é comparável a uma forma de adivinhação. Não é inverossímil ver um tom negativo em relação à adivinhação nesta definição. De todo modo, torna-se claro que o papel do adivinho e o do juiz são vistos, segundo esta definição, como práticas bastante distintas. É suposto que o juiz se apoie em evidências sólidas; o adivinho não. Talvez não devêssemos prosseguir esta abordagem de modo aprofundado; já vimos uma série de exemplos para o uso do sentido geral da adivinhação. Contudo, é importante notar que a analogia entre o adivinho e o juiz tem sido detectada em várias culturas, e tem sido frequentemente estudada na literatura antropológica. Não temos evidencias de que ela foi explicitamente feita por um intelectual romano, exceto nesta definição da divinatio.

O contraste entre a definição operatória que Cícero apresenta no início do De divinatione e a passagem do Pro Plancio em que o conhecimento dos adivinhos é explicitamente oposto ao conhecimento daquele que tem um conhecimento fundamentado de um caso dificilmente seria mais forte. A acentuada diferença dos contextos explica a aparente contradição; não faz sentido tentar resolvê-la. Ela é, no mínimo, um sinal claro da complexidade do sentido desta palavra, e da variedade de contextos nos quais ela foi utilizada: ele variava entre uma vaga referência à adivinhação, mais ou menos fundamentada, até a especulação livre e à experiência divinatória. 


\section{Prudentia, Prudens e Prudentes}

O conceito de prudentia é, em muitos aspectos, limítrofe ao de divinatio. ${ }^{27}$ As ocorrências de prudentia é muito mais frequente que o de divinatio: em Cícero é detectado 126 vezes. Há óbvias razões para isso: prudentia é um conceito filosófico, uma das virtudes mais significativas, e uma qualidade pessoal, que se aplica muito bem ao domínio político. Ela pode ser também um sinônimo para inteligência, ou sabedoria. Com sua usual agudeza na identificação de paralelos gregos para conceitos latinos, Cícero observa que era o equivalente latino de phronesis. Sem dúvida, esta é uma boa tradução, mas não faz justiça à visível relevância que prudentia tinha em assuntos divinatórios: ela deriva de pro-videre, de "ver antes, ver adiante".

Algumas passagens mostram que essa associação era ainda percebida e compreendida por alguns. ${ }^{28}$ Uma investigação exaustiva desta questão não entra no escopo deste artigo, mas eu gostaria de me concentrar em uma passagem do De haruspicum responsis de Cícero, que mostra algumas das linhas potenciais de contato entre divinatio e prudentia. Como lidava com a declaração de sua lealdade com os princípios gerais da adivinhação pública, Cícero reconhece a importância dos ensinamentos dos ancestrais, que criaram a estrutura na qual a adivinhação podia contribuir para o bom funcionamento do Estado. ${ }^{29}$ Cicero inicia sua declaração com

\footnotetext{
${ }^{27}$ Ver SANTANGELO, 2013, p. 56-65.

${ }^{28}$ Ver MALTBY, 1991, p. 504.
}

${ }^{29}$ Cicero, De haruspicum responsis 18: ego vero primum habeo auctores ac magistros religionum colendarum maiores nostros, quórum mihi tanta fuisse sapientia videtur ut satis superque prudentes sint qui illorum prudentiam non dicam adsequi, sed quanta fuerit perspicere possint; qui statas sollemnisque caerimonias pontificatu, rerum bene gerundarum auctoritates augurio, fatorum veteres praedictiones Apollinis vatum libris, portentorum expiationes Etruscorum disciplina contineri putaverunt; quae quidem tanta est ut nostra memoria primum Italici belli funesta illa principia, post Sullani Cinnanique temporis extremum paene discrimen, tum hanc recentem urbis inflammandae delendique imperi coniurationem non obscure nobis paulo ante praedixerint (Os termos que se referem diretamente à predição e à adivinhação estão em negrito: "Tenho, muitos termos que evocam conceitos de predição e previsão: os ancestrais eram prudentes, porque decidiram pôr em vigor uma série de práticas divinatórias; Cícero diz que, enquanto ele não poderia igualá-los em sua prudentia, estava plenamente ciente da contribuição que esta trouxera ao bem-estar do Estado. A lista que se segue confirma a impressão de que Cícero está lidando com as implicações etimológicas da prudentia: as profecias dos Livros Sibilinos eram chamadas fatorum veteres praedictiones, e os harúspices são elogiados, poucas linhas depois, por terem previsto com clareza os desenvolvimentos políticos recentes. Contudo, o elogio das virtudes da adivinhação não é genérico. A previsão dos ancestrais é celebrada porque eles decidiram limitar as potenciais escolhas das práticas divinatórias. A ênfase é em continere: o augúrio estabelece um limite ao uso do poder, os Livros Sibilinos provêm um quadro para as antigas declarações proféticas, e a disciplina etrusca estabelece regras para a expiação dos prodígios. Cicero certamente apresenta uma visão favorável do papel da adivinhação pública, mas ele a qualifica, ao dizer que não há adivinhação ordenada e significativa sem prudentia sem um conjunto de restrições e balanços ou, em última instância, sem ocorrer no interior de práticas políticas e legais. De fato, a adivinhação é útil e faz sentido somente porque é incluída em uma estrutura legal específica a bem estabelecida.

em primeiro lugar, nossos ancestrais como líderes e mentores ao demonstrar o respeito apropriado à religião - homens cuja sabedoria é para mim tão grande, homens que eram suficientemente, e mais do que suficientemente, prudentes, considerando-me, portanto, apto para, não digo igualar sua prudência, mas para estar totalmente ciente de quão grande era tal prudência, pois penso que as cerimônias regulares foram estabelecidas pelo pontificado, que a autoridade devida para a realização de todas as ações do Estado deriva do augurato, que as antigas previsões sobre nossos destinos estão contidas nos livros dos profetas de Apolo e as expiações dos prodígios estão contidas nos livros da doutrina dos etruscos, e esses últimos são tão relevantes que, citando apenas nossa própria memória individual, previram para nós, em sua língua obscura, em primeiro lugar o início da funesta Guerra Itálica, e depois o perigo extremo e a quase destruição do Estado no tempo de Sulla e Cina e, finalmente, essa recente conspiração para incendiar a cidade e destruir o império. Trad. Charles D. Yonge, modificada). 
A história do adjetivo prudens segue linhas semelhantes às do substantivo prudentia, e sua tradução é igualmente problemática (MALTBY, 1991, p. 504.) Ocasionalmente, contudo, vemos a reminiscência da sugestiva etimologia da palavra ressurgir: em uma carta endereçada a Plâncio em outubro de 45, Cícero relembra seus esforços para evitar a guerra civil e o ceticismo que suas iniciativas encontraram nos círculos optimates. ${ }^{30}$ Seus pares não conseguiram compreender que suas tentativas podiam ter evitado um derramamento de sangue sem precedentes: longe de ser temeroso, ele foi prudens. O que é muito interessante é a proximidade, não atestada alhures, de prudens (sábio, mas também aquele que é capaz de ver adiante) e praedicere.

$\mathrm{O}$ adjetivo prudens podia ser usado também no sentido legal - de fato, ele se tornou uma categoria legal muito cedo no desenvolvimento da jurisprudência romana. Uma das mais importantes respostas do jurista Q. Múcio Cévola (cos. 95 AEC) diz respeito a uma questão religiosa destacada: se o pretor que realizasse negócios em um dies nefastus deveria ser considerado culpado de um crime religioso. A ideia é que uma violação religiosa podia ser expiada com um sacrifício se o pretor tivesse violado a proibição de modo não intencional (imprudens); contudo, se a violação fosse intencional (si prudens

${ }^{30}$ Cicero, Ad familiares 4.14.1: quibus si vicissent ii, ad quos ego pacis spe, non belli cupiditate adductus accesseram, tamen intelligebam, et iratorum hominum et cupidorum et insolentium quam crudelis esset futura victoria, sin autem victi essent, quantus interitus esset futurus civium partim amplissimorum, partim etiam optimorum, qui me haec praedicentem atque optime consulentem saluti suae malebant nimium timidum quam satis prudentem existimari ("Pois se aqueles que são levados a se unir não por qualquer desejo de guerra, mas pela esperança da paz, se revelaram vitoriosos através das armas, eu não estava menos consciente de quão sanguinária teve de ser a vitória de homens tão furiosos, tão vorazes e tão arrogantes, e se, por outro lado, eles tinham de ser derrotados, tão esmagadora seria a ruína de meus concidadãos, alguns deles homens do mais alto nível, outros de grande caráter também, mas quem, quando eu predisse tudo isso e recomendei as medidas mais sábias para sua segurança, preferiram me ver como alguém indevidamente tímido, mas do que apropriadamente prudente"). dixit), a ofensa não era expiável. ${ }^{31}$ A palavra prudens é muito adequada para qualificar o conceito de ação deliberada: ela indica a conduta de alguém que está ciente das implicações de uma ação, e pode prever suas consequências. Cévola está aqui aplicando um princípio geral, de importância capital para a formação de um discurso sistemático em matérias legais. Seu interesse em estabelecer orientações gerais sobre alguns princípios abstratos é confirmado indiretamente pelo tópico que ele apresenta no mesmo contexto de que haveria outra importante exceção à proibição de fazer negócios em um dies nefastus: se houvesse algo cuja não realização seria prejudicial deveria ser feito. Esta resposta é um sintoma da emergência de um novo método. Por um lado, é

${ }^{31}$ Varro, De lingua Latina 6.4.30: praetor qui tum fatus est, si imprudens fecit, piaculari hostia facta piatur; si prudens dixit, Quintus Mucius aiebat eum expiari ut impium non posse ("o pretor que falou neste dia podia purificar a si mesmo pelo sacrifício de uma vítima expiatória, desde que tenha sido uma imprudência. Se ele deliberadamente agiu assim, Quinto Múcio afirma que ele não podia se purificar de nenhum modo, como aquele que cometera um ato ímpio". Trad. baseada em Maurizio Bettini). Cf. também Macróbio, Saturnalia 1.16.910: adfirmabant autem sacerdotes pollui ferias, si indictis conceptisque opus aliquod fieret. praeterea regem sacrorum flaminesque non licebat videre feriis opus fieri: et ideo per praeconem denuntiabant, ne quid tale ageretur, et praecepti neglegens multabatur. praeter multam vero adfirmabatur eum qui talibus diebus inprudens aliquid egisset porco piaculum dare debere: prudentem expiare non posse Scaevola pontifex adseverabat: sed Umbro negat eum pollui qui opus vel ad deos pertinens sacrorumve causa fecisset uel aliquid urgentem vitae utilitatem respiciens actitasset. Scaevola denique consultus, quid feriis agi liceret, respondit: quod praetermissum noceret (Os sacerdotes costumavam sustentar que um dia feriado foi profanado se, após ter sido devidamente promulgado e proclamado, qualquer trabalho tenha sido feito nele. Além disso, o sumo sacerdote e os flâmines não poderiam ver um trabalho em curso em um dia feriado, e por esta razão eles faziam uma advertência pública por um arauto que nada deste tipo fosse feito. Negligenciar este comando era algo punido por uma multa, e era dito que aquele que inadvertidamente fizera um trabalho em tais dias tinha, além da multa, que fazer uma expiação mediante o sacrifício de um porto. No caso de trabalhos realizados intencionalmente nenhuma expiação era possível, de acordo com o pontífice Cévola; mas Umbro disse que fazer um trabalho que concernisse aos deuses, ou que fosse conectado com uma cerimônia religiosa, ou qualquer trabalho urgente ou de importância vital não contaminava o agente. Trad. baseada em Percival V. Davies). 
possível ver um esforço para encontrar soluções mais sensatas para facilitar a administração dos assuntos políticos e religiosos; por outro lado, há um esforço para estabelecer princípios gerais que podiam ter amplas implicações. ${ }^{32} \mathrm{Na}$ verdade, há evidencia para o uso posterior do termo prudens em textos legais não apenas com referência ao comportamento criminoso intencional, mas também indicando um padrão de responsabilidade e, mais genericamente, orientando alguém que está elaborando um testamento ou fazendo uma promessa sob condições. ${ }^{33}$

Outro uso de prudens, contudo, é muito mais interessante para nossos propósitos. Podemos ver em Plauto que o adjetivo pode ser acompanhado pelo genitivo para se referir a um tipo de conhecimento ou previsão que é aplicada a uma forma específica de conhecimento. ${ }^{34}$ Este uso é frequente, às vezes no genitivo, outras no ablativo, e define consistentemente uma forma de conhecimento prático, um discernimento de situações. Este sentido é amplamente atestado, novamente a partir do século I AEC, com uma variedade de associações: no pro Quinctio de Cícero, o paterfamilias é ceterarum rerum et prudens et attentus (11); o Conon de Nepos é um excelente comandante militar, porque ele é prudens rei militaris et diligens (1.2); segundo Tácito (Ann., 3.69), Tibério ocasionalmente conseguia controlar sua costumeira agressividade e se moderar - ele era prudens moderandi. Quando o mitógrafo Higino aborda a figura de Idmon de Argos, o primeiro argonauta a morrer durante a expedição, nota que ele foi capaz de prever sua morte através da observação do voo dos pássaros, e ainda assim decidiu se juntar à expedição. Higino destaca que Idmon era um perito em adivinhação (augurio prudens) (Higino, Fabulae, 14.11).

\footnotetext{
32 Sobre esta passagem, ver SCHEID, 2006, e TELLEGEN-COUPERUS, 2012. Ver também, sob um diferente viés, BETTINI, 2008, p. 330-332.

33 Gélio, Noctes Atticae 20.1.17 (citando o tratado de Labeão sobre as Doze Tábuas). Ver também Q. Cervídio Cévola em Digesta 28.5 .86 sobre o testator, e Javoleno em Digesta 24.3.66.4 (citando Labeão) sobre a cláusula; um inventário completo de referências em MEINHART, 1985, p. 1293-1294.

${ }^{34}$ e.g. Plauto, Captiva 45, em que prudens é usado em oposição a insciens boni.
}

O termo augurium é aqui usado em um sentido geral de "faculdade de adivinhação". (Virgílio, Aeneis, 12.394; Ovídio, Metamorphoses 13.650). O uso de prudens é também muito interessante por várias razões. Higino foi um escritor ativo no período augustano, e sabia que a palavra prudens, então, era usualmente associada a formas de conhecimento ligadas ao campo religioso e, de fato, à esfera jurídica. Ele também sabia, decerto, que a partir da geração de Cícero (pelo menos; é possível que evidências anteriores estejam perdidas para nós) o adjetivo prudens podia ser utilizado como um substantivo. Indiscutivelmente, seu sentido original era muito próximo ao do adjetivo: o prudens é um expert, alguém que tem um conhecimento especial em um assunto específico. Este é o sentido que encontramos no início do Orator, por exemplo, no qual Cícero menciona o tipo de crítica que pode partir de homens doutos e sábios (1.1: reprehensionem doctorum atque prudentium). Esta definição de prudens como "a pessoa que sabe" rapidamente se tornou parte do jargão legal. ${ }^{35} \mathrm{O}$ papel das responsa prudentium na divisão das partes constituintes da lei romana de Gaio é bem conhecido: os prudentes eram aqueles aptos a se pronunciar sobre questões legais e emitir opiniões fundamentadas e vinculativas. ${ }^{36}$ Se os pareceres de dois prudentes sobre certo tema fossem iguais, esperava-se que o juiz seguisse este consenso; se estivessem em desacordo, o juiz teria liberdade para escolher que curso de ação

35 TELLEGEN, TELLEGEN-COUPERUS, 2000, p. 186-187 oferecem uma lúcida demonstração do motive da analogia entre advogados romanos (iurisprudentes, iurisperiti e iureconsulti) e os modernos Fachjuristen não se sustenta.

${ }^{36}$ Gaio, Institutiones 1.2: constant autem iura populi Romani ex legibus, plebiscitis, senatus consultis, constitutionibus principum, edictis eorum, qui ius edicendi habent, responsis prudentium (O direito romano consistem em estatutos, plebiscitos, senatusconsulta, constituições dos imperadores, editos dos magistrados autorizados a emiti-los e respostas dos juristas); 1.7: responsa prudentium sunt sententiae et opiniones eorum, quibus permissum est iura condere. quorum omnium si in unum sententiae concurrunt, id, quod ita sentiunt, legis uicem optinet; si uero dissentiunt, iudici licet quam uelit sententiam sequi; idque rescripto diui Hadriani significatur (As respostas dos juristas são as decisões e opiniões de pessoas autorizadas a estabelecerem a lei. Se forem unânimes, sua decisão tem força de lei; se divergentes, o juiz pode seguir a opinião que escolher, pois ele é regido por um edito do falecido imperador Adriano) 
considerava mais adequado. A reflexão de Gaio é profundamente enraizada no contexto do século II EC, no qual o poder do imperador provê o único quadro no qual a solução de disputas legais poderia se dar: os advogados podiam expressar suas opiniões porque eram autorizados a isso pelo imperador. ${ }^{37}$ Contudo, o cerne da discussão radica em uma disputa muito anterior: o exercício de Gaio é uma tentativa de oferecer uma lista das fontes do direito e contribuir para uma tradição do início do século I AEC, com as tentativas de identificar os componentes do ius na Rhetorica ad Herennium e no De inventione e nos Topica de Cícero. ${ }^{38} \mathrm{O}$ debate sobre as partes iuris teve continuidade na República tardia e no primeiro Principado, e o reconhecimento do papel dos advogados pode ser visto apropriadamente como uma consequência da crescente importância do papel dos precedentes nas discussões tardo-republicanas.

Mais uma vez, pode-se pensar em paralelos com a prática divinatória. Precedentes tinham um papel significativo nas principais áreas da adivinhação pública romana. Os harúspices baseavam suas respostas em uma disciplina, um corpo de conhecimentos teóricos que também estava codificado em textos (nenhum dos quais sobreviveu) e era mantido sobre o patronato do governo romano. Os Livros Sibilinos e os rituais que eram realizados pelos decemviri s.f. dependiam de um corpo similar de conhecimentos: John Scheid pode coerentemente cunhar o conceito de jurisprudence divinatoire (SCHEID, 1998, p. 28). O mesmo princípio se aplica ao trabalho de reunião do material que constituiu o novo corpus dos Livros, após o incêndio de 83 AEC: reunir os textos de várias comunidades na Itália e além (notadamente Eritreia, na Ásia Menor), e estabelecer aqueles que podiam ser escolhidos para serem incluídos na nova coleção implicava um conhecimento dos precedentes. Finalmente, o próprio procedimento que levou

\footnotetext{
${ }^{37}$ Algumas discussões recentes do ius respondendi (todas referidas a bibliografia anterior): TELLEGEN-COUPERUS, 1993, p. 95-98; SCHIAVONE, 2005, p. 330-332 (esp. 332: “si respira um'aria già da tardoantico"); LEESEN, 2010, p. 335-340; TUORI, 2010, p. 48-55.

${ }^{38}$ Ver FERRARY., 2007.
}

ao tratamento e à expiação dos prodígios implicava um conhecimento especializado que englobava os relevantes precedentes. Não são claros os critérios que o Senado usava para decidir quando os harúspices ou os (quin)decemviri eram consultados. Parece que os (quin)decemviri e os Livros Sibilinos eram consultados quando um grupo de prodígios ocorria, enquanto os harúspices eram geralmente consultados quando uma resposta era necessária a uma ocorrência isolada e específica - mas este princípio se aplica ao período entre 200 e 167, coberto pela narrativa de Lívio, e menos para o restante dos séculos II e I AEC, quando o papel dos harúspices se tornou mais proeminente (NORTH, 1967, p. 567595; SANTANGELO, 2013, p. 84-89). Estabelecer um padrão é problemático, mas é certo que o procedimento que conduzia à expiação dos prodígios tinha implicações legais, e que um conjunto de práticas estava, de fato, estabelecido.

Para concluir, voltemos ao problema dos precedentes. O máximo que podemos fizer a partir do Digesto, a emergência do significado de prudens como "advogado" data do início do Principado. Ele não é encontrado em juristas tardo-republicanos como Cévola e Sulpício, ou mesmo depois em Labeão, mas sua não existência não pode ser presumida. Não podemos descartar a ideia de que fosse o caso, claro, pois muitos textos foram perdidos, neste e em outros gêneros literários. Dois pontos, contudo, devem ser levantados a este respeito.

Em primeiro lugar, o conceito de responsa prudentium. É decorrente do texto de Gaio que ele foi usado e codificado algum tempo antes de sua definição. O modelo implicado é claro: os juristas agiam através de respostas, em manifestações específicas sobre questões específicas. Eles usavam seu conhecimento para resolver um caso específico. Estamos, decerto, no contexto de uma característica bem estudada e estabelecida da vida intelectual romana entre a República tardia e o início do Principado: a emergência e consolidação de um número de ramos especializados do conhecimento e o estabelecimento de diferentes discursos profissionais. O nascimento da jurisprudência é parte fundamental deste processo. Trata-se da disciplina na qual a relação entre o geral e o particular, entre 
o universal e o local, entre os princípios e as práticas encontram alguns de seus resultados mais marcantes e instrutivos. Este artigo não é o lugar para uma exploração profunda deste tema, mas é importante destacar como o desenvolvimento semântico da palavra prudens ocorre neste contexto: vemos sua evolução de adjetivo a substantivo e, de modo mais relevante, sua aplicação do domínio do "bom senso, sabedoria, expertise" ao das novas ciências que se constituíram em Roma entre os séculos II e I AEC. A expressão responsa prudentium é também interessante por outra razão: sua complexidade e, mesmo, seu poder evocador. Já discutimos a etimologia de prudens e de prudentia, e sua afinidade explícita com a esfera da predição e, de fato, da adivinhação.

Além disso, a palavra responsum traz à mente os modos pelos quais a adivinhação foi e é praticada em Roma e alhures: ela acontecia, e ainda acontece, principalmente através de uma série de declarações de peritos dedicados a um problema especifico, e é baseada em um corpo de observações específicas. ${ }^{39}$ É fascinante ver os responsa e os prudentes - dois conceitos que têm essas profundas ressonâncias divinatórias - justapostos formando uma categoria intelectual que marca o triunfo da jurisprudência romana, e sua transformação em um importante elemento constituinte do direito romano. As fronteiras entre divinatio e prudentia são mais porosas do que se costuma pensar.

\section{LAW AND DIVINATION IN THE LATE ROMAN REPUBLIC}

Abstract: This paper deals with the intersections between law and divination in the late Roman Republic. It focuses mostly on the evidence of Cicero, and on some terms that feature prominently in his work, notably divinatio and prudentia. Some comparative material is also brought into the discussion, as well as the evidence of other Roman authors, notably Plautus. An important level of affinity between law

${ }^{39}$ Cf. ver a importante discussão em Schiavone, 2005, p. 91110. and divination is emphasised: their heavy reliance on specialised knowledge and on authoritative responses.

Keywords: Divination, prediction, law, foresight, jurisprudence, knowledge, Roman Republic, Cicero.

\section{REFERÊNCIAS BIBLIOGRÁFICAS}

BAKER, John H. An Introduction to English Legal History, $3^{\text {rd }}$ ed. London: Butterworth, 1990.

BARTLETT, Robert. Trial by Fire and Water. The Medieval Judicial Ordeal. Oxford: Clarendon Press, 1986.

BEARD, Mary. Cicero and Divination: the Formation of a Latin Discourse. Journal of Roman Studies, Cambridge, 76, 1986, p. 33-46.

BETTINI, Maurizio. Weighty Words, Suspect Speech: fari in Roman Culture. Arethusa, Baltimore, 41, 2008, p. 313-375.

DOTSON, Brandon. Divination and Law in the Tibetan Empire: the Role of Dice in the Legislation of Loans, Interest, Marital Law and Troop Conscription. In: KAPSTEIN, Matthew T.; DOTSON, Brandon. (ed.) Brill's Tibetan Studies Library 14. Leiden-Boston, Brill, 2007, pp. 1-78.

EVANS-PRITCHARD, Edward E. Witchcraft, Oracles, and Magic among the Azande. Oxford: Oxford University Press, 1937.

FERRARY, Jean-Louis. Le droit naturel dans les exposés sur les parties du droit des traités de rhétorique. In: MANTOVANI, Dario; SCHIAVONE, Aldo. (ed.) Testi e problemi del giusnaturalismo romano. Pubblicazioni del Cedant 3. Pavia, 2007, p. 75-94.

FÖGEN, Marie. Th. Die Enteignung der Wahrsager. Studien zum kaiserlichen Wissensmonopol in der Spätantike. Frankfurt, 1993.

GRUEN, Erich S. The Dolabellae and Sulla. American Journal of Philology, Baltimore, 87 (1966), p. 385-399.

HARRIES, Jill H. Cicero and the Jurists. From Citizens' Law to the Lawful State. London: Duckworth, 2006.

LEESEN, Tessa. G. Gaius Meets Cicero. Law and Rhetoric in the School Controversies. Legal History Library 2. Leiden: Brill, 2010.

LEWIS, Mark. E. The Early Chinese Empires. Qin and Han. Cambridge: The Belknap Press of Harvard University Press, 2007.

LINDERSKI, Jerzy. Cicero and Divination. Parola del Passato, Bari, 37, 1982, p. 12-38. 
MALTBY, Robert. A Lexicon of Ancient Latin Etymologies. ARCA Classical and Medieval Texts, Papers and Monographs 25. Leeds: Francis Cairns, 1991, p. 192-193.

MAUL, Stefan. M. How the Babylonians Protected Themselves against Calamities Announced by Omens. In: ABSUCK, Tzvi. VAN DER TOORN, Karel. (ed.) Mesopotamian Magic: Textual, Historical and Interpretive Perspectives. Studies in Ancient Magic and Divination 1. Groningen, 1999, p. 123-129.

MEINHART, Michael. Vocabularium iurisprudentiae Romanae. 4.3, 4a ed.. Berlin-New York, 1985.

NORTH, John. A. The Inter-Relation of State Religion and Politics in Roman Public Life from the End of the Second Punic War to the Time of Sulla (Diss. Oxford, 1967), p. 567-595.

RAWSON, Elizabeth D. Intellectual Life in the Late Roman Republic. London: Duckworth, 1985.

RIPAT, Pauline. Expelling Misconceptions: Astrologers at Rome. Classical Philology, Chicago, 106, 2011, p. 115154.

ROSENSTEIN, Nathan. Sorting Out the Lot in Republican Rome. American Journal of Philology, Baltimore, 116, 1995, pp. 43-75.

SANTANGELO, Federico. Divination, Prediction and the End of the Roman Republic. Cambridge: Cambridge University Press, 2013, p. 246-258.

SCHEID, John. La Parole des dieux: L’Originalité du dialogue des Romains avec leurs dieux. Opus, São Paulo, 6-8, 1987-1989, p. 125-136

. Les Livres Sibyllins et les archives des quindécemvirs. In: MOATTI, Claude. (ed.) La Mémoire perdue. Recherches sur l'administration romaine. Rome: École Française de Rome, 1998, p. 11-26.

. Oral Tradition and Written Tradition in the Formation of Sacred Law in Rome. In: ANDO, Clifford. RÜPKE, Jörg. (ed.) Religion and Law in Classical and Christian Rome. Stuttgart: PawB, 2006, p. 14-33.

SCHIAVONE, Aldo. IUS. L'invenzione del diritto in Occidente. Biblioteca di cultura storica, Turin, 254, 2005.

SCHIESARO, Alessandro. Didaxis, Rhetoric, and the Law in Lucretius. In: HEYWORTH, Stephen. J. FOWLER, Peta G. HARRISON, Stephen J. Classical Constructions. Papers in Memory of Don Fowler, Classicist and Epicurean. Oxford: Oxford University Press, 2007, p. 62-90.

SCHOFIELD, Malcolm. Cicero for and against Divination. Journal of Roman Studies, Cambridge, 76, 1986, p. 47-65

SCHULTZ, Celia E. Argument and Anecdote in Cicero's De Divinatione. In: HARVEY Paul B. CONYBEARE, Catherine. (ed.) Maxima debetur magistro reverentia: Essays on Rome and the Roman Tradition in Honor of Russel T. Scott. Biblioteca di Athenaeum 54. Como: New Press edizioni, 2009, p. 193-206.
SIMMON, Donald C. Efik. Divination, Ordeals and Omens. Southwestern Journal of Anthropology, Albuquerque, 12, 1956, p. 223-228.

STANGL, Thomas. Pseudoasconiana. Textgestaltung und Sprache der anonymen Scholien zu Ciceros vier ersten Verrinen auf Grund der erstmals verwerteten altesten Handschriften. Studien zur Geschichte und Kultur des Altertums 2.4-5. Paderborn: F. Schoningh, 1909

STEWART, Roberta. Public Office in Early Rome. Ritual Procedure and Political Practice. Ann Arbor: The University of Michigan Press, 1998, pp. 12-51.

TELLEGEN, Jan W.; TELLEGEN-COUPERUS, Olga E. Law and Rhetoric in the causa Curiana. Orbis luris Romani, Trnava, 6, 2000, p. 171-202.

A Short History of Roman Law. London-New York: Routledge, 1993.

Sacred Law and Civil Law. In: TELLEGENCOUPERUS Jan. W. (ed.) Law and Religion in the Roman Republic. Leiden: Brill, 2012, p. 147-164.

THOMAS, Keith. Religion and the Decline of Magic. Studies in Popular Beliefs in Sixteenth and Seventeenth Century England. London: Penguin, 1971.

TIMPANARO, Sebastiano. Alcuni fraintendimenti del De Divinatione. In: TIMPANARO, Sebastiano. Nuovi contributi di filologia e storia dela língua latina. Bologna: Pātron Editore, 1994, p. 241-264.

TUORI, Kaius. A Place for Jurists in the Spaces of Justices. In: DE ANGELIS, Francesco. (ed.) Spaces of Justice in the Roman World. Columbia Studies in the Classical Tradition 35. Leiden-Boston: Brill, 2010, p. 43-65.

VAN DER VELDEN. Bastian D. Een rechtsgeschiedenis van Curaçao; ik lach met Grotius en alle die prullen van boeken. Willemstad: CARIB publishing, 2008.

WADE MANSELL, Wade. THOMSON, Alan. METEYARD, Belinda. A Critical Introduction to Law. $3^{\text {rd }}$ ed. London: Routledge, 2004, pp. 31-35.

\footnotetext{
* Nota do Autor: Sou muito grato a Claudia Beltrão por viabilizar a republicação deste artigo e pela excelente tradução em português. Eu mantive o texto virtualmente no mesmo formato com que foi publicado em 2012, com exceção de algumas breves correções e inclusões bibliográficas.

Nota da Tradutora: Agradeço ao Dr. Federico Santangelo e à Brill Publishers/Koninklijke Brill a permissão para a tradução deste texto, originalmente publicado como parte integrante da coletânea: TELLEGEN-COUPERUS, O. (ed.) Law and Religion in the Roman Republic. Leiden, Brill, 2012. ISBN: 9789004218505.
} 